\title{
Educação superior para pessoas com deficiência: com a palavra estudantes universitários da cidade de Jequié - $\mathrm{Ba}^{1}$
}

Resumo: Com o objetivo de conhecer a opinião dos estudantes universitários
sobre Educação Superior para pessoas com deficiência, aplicou-se um questio-
nário a 147 estudantes universitários da cidade de Jequié-BA. A análise dos
dados revelou que ainda são poucas as pessoas com deficiência no ensino
superior nesta cidade e que $91,16 \%$ dos pesquisados já ouviram falar de inclu-
são, todavia, $58,82 \%$ não apresentaram definição satisfatória sobre a inclusão.
Cerca de $14,29 \%$ dos pesquisados já disseram ter presenciado a discriminação
das pessoas com deficiência nas instituições de ensino superior. Estes dados
permitiram constar que as pessoas com deficiência ainda encontram significa-
tivos obstáculos para o ingresso e permanência no ensino superior.
Palavras-chave: Educacão inclusiva. Pessoa com deficiência. Ensino superior.

Historicamente, as pessoas com deficiência sempre foram excluídas da sociedade, colocadas à margem e impedidas de frequentar ambientes tais como escolas, universidades, supermercados, cinemas, bancos, dentre outros ambientes, que fazem parte da vida do cidadão comum, devido ao preconceito, às barreiras arquitetônicas, às dificuldades de transporte e/ou de comunicação que dificultam a inserção e o convívio dessas pessoas com as pessoas sem deficiência.

Apesar disso, somente a partir 1960, surgiu a ideia de integração das pessoas com deficiência, objetivando incluir educandos já anteriormente excluídos. Esta se apoiou em movimentos a favor da integração das pessoas com deficiência, surgidos nos países nórdicos e que questionavam a segregação social e educacional dessas pessoas. (MANTOAN, 1998)

A Educação Inclusiva surgiu alguns anos depois, em 1975, nos Estados Unidos da América, como um movimento em defesa dos direitos das pessoas com deficiência, através da Lei pública $n^{\circ} .94142$ (MRECH, 2005), tendo como um dos princípios o direito das pessoas com deficiência frequentarem as instituições de ensino reforçado mais tarde pela Declaração de Salamanca. (SALAMANCA, 1994) Neste contexto, a Educação Inclusiva, no que concerne às pessoas com deficiência, pode ser definida como a inserção completa dessas pessoas na rede regular de ensino, em todos os seus níveis (do fundamental ao superior), garantin-
Adriana Silva Barbosa

Universidade Estadual do Sudoeste da Bahia drybarbosa@yahoo.com.br

Ana Cristina Santos Duarte Universidade Estadual do Sudoeste da Bahia cristina@uesb.br

(1) Artigo científico elaborado com base em dados da Monografia de pós-graduação Concepções estudantes de universitários sobre a educação inclusiva no ensino superior, na cidade de Jequié - BA elaborada como requisito à obtenção do Título de Especialista em Metodologia do Ensino Superior pelas Faculdades Integradas de Jequié (FIJ). 
do a elas as mesmas oportunidades de aprendizado ofertadas às pessoas sem deficiência.

No Brasil, o primeiro documento legal a garantir o direito à educação para as pessoas com deficiência foi a Constituição Federal de 1988, que afirma que a educação é direito de todos, garantindo auxílio financeiro, integração social, assistência educacional, proibindo a discriminação no trabalho, estabelecendo cotas para pessoas com deficiência no serviço público e obrigando a facilitação do acesso a prédios e transportes públicos. (BENEVIDES, 2004)

Em 1999 foi editado neste país, o Decreto n 3.298/1999, que dispõe sobre a Política Nacional para a Integração da Pessoa Portadora de Deficiência, e define a deficiência como "[...] toda perda ou anormalidade de uma estrutura ou função psicológica, fisiológica ou anatômica que gere incapacidade para o desempenho de atividade dentro do padrão considerado normal para o ser humano" (BRASIL, 1999), classificando-a em auditiva, física, mental, visual e múltipla.

Apesar dos avanços da legislação, Prieto (2003) lembra que $14,5 \%$ da população brasileira tem algum tipo de deficiência e que grande parte dessas pessoas possui baixa escolaridade e encontrase fora do mercado de trabalho. Dessas, $40 \%$ encontram-se na Região Nordeste do Brasil. No estado da Bahia, as pessoas com deficiência correspondem a 15,65\% da população. (NERI, et al., 2003) Isto denota a necessidade de profundas mudanças sociais, uma vez que incluir é permitir que pessoas, antes excluídas da sociedade, passem a exercer seus direitos de cidadãos e a fazer parte do contexto social em todos os seus níveis (educação, saúde, mercado de trabalho, etc.), o que significa que a inclusão envolve mudanças em vários setores da sociedade e a conscientização das pessoas da necessidade de reconhecer a importância das pessoas com deficiência, uma vez que elas têm muito a contribuir para o desenvolvimento social.

Diante disso, o ensino superior deve incentivar de forma mais intensa a geração de conhecimento (através de pesquisas e da formação de profissionais) e também conscientizar a sociedade sobre a importância da valorização do ser humano, inclusive daqueles com limitações físicas, sensoriais e/ou mentais, facilitando o ingresso dessas pessoas no mercado de trabalho, contribuindo assim para que elas ocupem seu lugar na sociedade enquanto pessoas 
completas, que também podem refletir, gerar conhecimento, constituir uma família, ser economicamente ativos e financeiramente independentes. Assim, este trabalho teve como objetivo verificar a concepção de estudantes universitários sobre Educação Inclusiva e conhecer a opinião deles sobre a Educação Superior para pessoas com deficiência.

\title{
Metodologia
}

\author{
Cenário da pesquisa
}

Este trabalho foi realizado na cidade de Jequié, que se encontra localizada na região Sudoeste da Bahia e possui cerca de 145.964 habitantes, segundo dados do IBGE (2007), distante $365 \mathrm{Km}$ da cidade de Salvador. Além disso, esta cidade tem como municípios limítrofes Ipiaú, Aiquara, Apuarema, Boa Nova, Itagi, Jaguaquara, Jitaúna, Lafaiete Coutinho, Manoel Vitorino e Maracás, com os quais se relaciona também socioeconomicamente.

A cidade de Jequié possui quatro instituições de ensino superior, dentre as quais apenas uma é pública e as demais são particulares. Dentre as instituições particulares presentes na cidade, uma se dedica ao ensino presencial, outra possui o ensino presencial e a distância, e a outra se dedica ao ensino a distância. Desse modo, escolheu-se a instituição de ensino superior pública e a instituição de ensino superior particular com ensino presencial como campo de coleta de dados devido ao fato de os estudantes de ensino superior presencial passarem mais tempo convivendo no ambiente da instituição de ensino superior.

As instituições de ensino superior pesquisadas possuem uma considerável abrangência, recebendo estudantes das cidades limítrofes a Jequié. Em 2007, a instituição de ensino superior privada tinha 585 alunos matriculados na graduação, enquanto a instituição pública possuía 1893. A instituição de ensino superior pública destaca-se por possuir também estudantes de outros municípios da Bahia (não apenas limítrofes com a cidade de Jequié) e também de outros estados como Minas Gerais e São Paulo. Em ambas as instituições, na época da pesquisa, não havia registro de alunos com deficiência no ensino superior nas secretarias dos cursos. 
Tipo de pesquisa, amostra e instrumento de coleta de dados

Antes de ser iniciado, este estudo foi analisado e aprovado pelo Comitê de Ética em Pesquisa da UESB (protocolo 037/2007), seguindo a Resolução 196/96 (CONSELHO NACIONAL DE SAÚDE, 1996) em todas as suas fases.

Metodologicamente, este estudo caracteriza-se como uma pesquisa quantitativa descritiva. A pesquisa quantitativa traduz em números opiniões e informações para analisá-las estatisticamente (SILVA; MENEZES, 2005) e, de acordo com Gil (2008), a pesquisa descritiva tem como objetivo estudar as características de um determinado grupo. Portanto, optou-se por este tipo de pesquisa por ser adequado para o alcance dos objetivos da pesquisa.

Para a coleta de dados, optou-se por um questionário, técnica esta bastante empregada em pesquisas não experimentais (BENZE, 2001), e que permite atingir um grande número de pessoas, além de garantir o anonimato dos participantes da pesquisa e não expor os mesmos à influência do pensamento do pesquisador. (GIL, 2008) O questionário elaborado contemplou as seguintes questões: presença de pessoas com deficiência nas instituições pesquisadas, conhecimento dos estudantes universitários sobre a educação inclusiva, opinião dos estudantes universitários sobre o ingresso de pessoas com deficiência no ensino superior e a existência ou não (sob a perspectiva dos participantes) de discriminação de pessoas com deficiência no ensino superior.

Participaram da pesquisa 147 estudantes, sendo 74 de instituição pública e 73 de instituição privada. Dos 147 participantes, apenas cinco possuem algum tipo de deficiência. A escolha dos participantes da pesquisa se deu de forma aleatória, conforme a disponibilidade dos mesmos para responder ao questionário. Ao aceitar participar da pesquisa respondendo ao questionário, a pesquisador informava o objetivo da mesma e os participantes assinavam o Termo de Consentimento Livre e Esclarecido (TCLE).

\section{Resultados e discussão dos dados}

Os dados coletados através do questionário foram analisados utilizando-se a Estatística Descritiva (análise univariada) e foram dispostos em gráficos e tabelas. 


\section{Presença de pessoas com deficiência nas instituições pesquisadas na cidade de Jequié(Ba)}

Ao serem perguntados se possuíam alguma deficiência, apenas 3,40\% dos estudantes responderam que sim, enquanto $96,60 \%$ afirmaram que não (Gráfico 1). Dentre as pessoas com deficiência que participaram da pesquisa, 100\% delas possuíam algum tipo de deficiência física (Tabela 1).

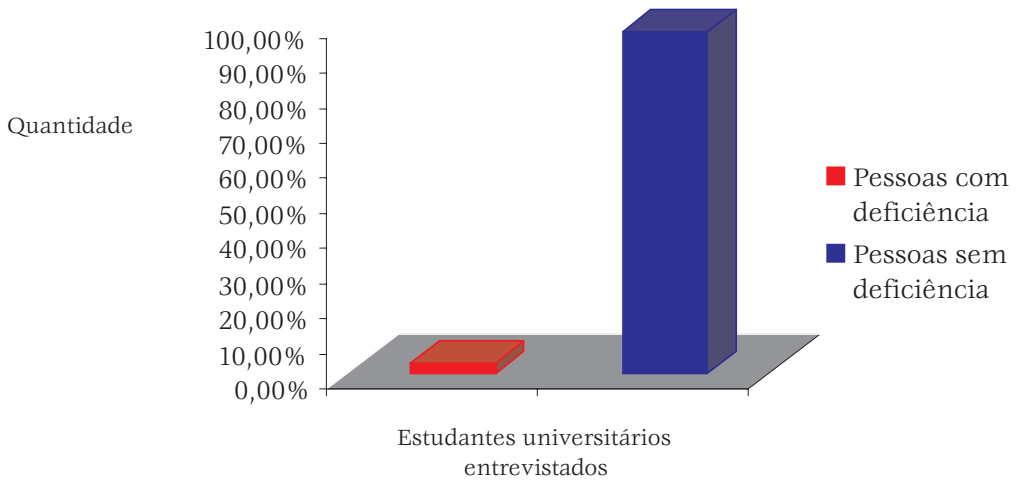

Gráfico 1: Presença de pessoas com deficiência nas instituições pesquisadas. Fonte: Dados da pesquisa.

\begin{tabular}{lll}
\hline Tipo & Porcent. & Quant. \\
\hline Física (não especificou) & $20 \%$ & 1 \\
Locomove-se com a ajuda de muletas & $20 \%$ & 1 \\
Uma perna mais curta que a outra & $20 \%$ & 1 \\
Diminuição da coordenação motora & $20 \%$ & 1 \\
Pólio na perna direta, com efeito na esquerda & $20 \%$ & 1 \\
TOTAL & $100 \%$ & 5 \\
\hline
\end{tabular}

Fonte: Dados da pesquisa.

Tabela 1: Tipo de deficiência dos estudantes universitários pesquisados (conforme especificado pelos mesmos).

Estes dados demonstram que ainda é pouco expressiva a presença de pessoas com deficiência no ensino superior na cidade de Jequié-BA. As pessoas com deficiência ainda são minoria nas instituições de ensino superior, não correspondendo nem a $1 \%$ dos estudantes de instituições de grande porte como a Universi- 
dade de Brasília (UnB) e a Universidade Católica de Brasília (UCB). Apesar disso, Bassete (2007) relata que, segundo o Censo da Educação Superior de 2005, o número de matrículas de pessoas com deficiência no ensino superior cresceu cerca de 179,4\% entre 2000 e 2005, sendo mais expressivo o aumento do ingresso dessas pessoas nas instituições de ensino superior particulares. Deve-se ressaltar também que, segundo Bassete (2007), o tipo de deficiência mais comum no ensino superior é a deficiência física e a menos comum é a deficiência mental, o que corrobora os dados do presente estudo, que encontrou apenas pessoas com deficiência física no ensino superior.

\section{Conhecimento dos estudantes universitários sobre inclusão}

Ao serem indagados se já ouviram falar em inclusão, 91,16\% dos estudantes universitários afirmaram já ter ouvido falar, enquanto 5,44\% disseram não ter ouvido falar sobre inclusão e 3,40\% não responderam. Este dado pode ser explicado pelo fato de o público-alvo deste estudo ser estudantes universitários e também por esta temática encontrar-se, atualmente, bastante presente na mídia. Apesar disso, 18,95\% dos participantes não responderam à pergunta (Tabela 2). Destaca-se, aqui, a fala de um dos estudantes com deficiência integrantes da amostra:

A questão da inclusão de pessoas com necessidades educacionais especiais na rede de ensino insere-se no contexto das discussões, cada vez mais em evidência, relativas à integração de pessoas portadoras de deficiências enquanto cidadãos, com seus respectivos direitos e deveres de participação e contribuição social. A Educação Inclusiva não surgiu ao acaso, ela é um produto histórico de uma época e de realidades educacionais contemporâneas, uma época que exige o abandono dos estereótipos e preconceitos. 


\begin{tabular}{lcc}
\hline Resposta & \% & Qtde \\
\hline $\begin{array}{l}\text { Inserção de pessoas com deficiência na } \\
\text { sociedade. }\end{array}$ & $17,65 \%$ & 27 \\
$\begin{array}{l}\text { Inserção de pessoas com deficiência na } \\
\text { educação/ ensino superior. }\end{array}$ & $14,38 \%$ & 22 \\
$\begin{array}{l}\text { Igualdade de direitos entre pessoas com e sem } \\
\text { deficiência, sem discriminação. }\end{array}$ & $7,84 \%$ & 12 \\
$\begin{array}{l}\text { Separação e distanciamento das pessoas na } \\
\text { sociedade. }\end{array}$ & $1,31 \%$ & 2 \\
Não respondeu. & $18,95 \%$ & 29 \\
Outras respostas. & $39,87 \%$ & 61 \\
TOTAL & $100,00 \%$ & 153 \\
\hline
\end{tabular}

Tabela 2 - Conhecimento sobre inclusão

Fonte: Dados da pesquisa.

Verifica-se na Tabela 2, que a maioria dos participantes, $58,82 \%$, possui pouco conhecimento sobre inclusão, pois não respondeu ou respondeu de forma equivocada, como: "é importante/ relevante", "inclusão de pessoas excluídas", "inclusão de pessoas menos favorecidas", "inclusão digital e em novas tecnologias", "inclusão no mercado de trabalho", "muito pouco ou não tem informação sobre inclusão", "não existem escolas exclusivas para pessoas com deficiência", "pessoas ou coisas inseridas em alguma coisa, em algum grupo ou instituição", "relacionado à conscientização de pessoas 'normais'".

Ferreira (2005) relata que a educação inclusiva pode ser conceituada de várias formas, sendo considerada por muitos autores como uma filosofia que valoriza a diversidade, por outros como um movimento que preconiza a educação para todos, podendo ser considerada também como um processo ou como uma prática. Apesar de poder ser conceituada de várias formas, este autor lembra que a educação inclusiva deve criar estratégias contínuas e diversificadas que oportunizem o aprendizado dos alunos, independente de suas deficiências, além de criar bases para a melhoria da instituição de ensino e para a contínua capacitação dos professores. Isso significa que a educação inclusiva requer um novo olhar da sociedade sobre a necessidade de se criar ambientes menos restritivos para que a educação seja, de fato, para todos. (GARCEZ; SACALOSKI, 2002) 


\section{Opinião dos estudantes universitários sobre o ingresso de pessoas com deficiência no ensino superior}

Ao serem convidados a opinar sobre a educação inclusiva no ensino superior (Tabela 3), 11,70\% dos estudantes responderam que "as pessoas com deficiência têm direito à educação, ao ensino superior", enquanto 7,06\% disseram que "pessoas com deficiência têm a mesma capacidade intelectual e profissional" e 5,85\% afirmaram que "todos têm o mesmo direito".

\begin{tabular}{|c|c|c|}
\hline Opinião dos Estudantes Universitários & $\%$ & Qtde \\
\hline As pessoas com deficiência, às vezes, não são responsáveis. & $0,58 \%$ & 1 \\
\hline Uma coisa absurda. & $0,58 \%$ & 1 \\
\hline $\begin{array}{l}\text { Se estiverem aptos e capazes para isso, tiverem o } \\
\text { conhecimento mínimo necessário. }\end{array}$ & $1,75 \%$ & 3 \\
\hline $\begin{array}{l}\text { O governo precisa incentivar e aumentar a inclusão de pessoas } \\
\text { com deficiência no ensino superior (criar uma política de } \\
\text { inclusão). }\end{array}$ & $3,51 \%$ & 6 \\
\hline Não respondeu. & $3,51 \%$ & 6 \\
\hline $\begin{array}{l}\text { As instituições de ensino superior não estão preparadas para a } \\
\text { educação inclusiva, o que a torna precária ou inexistente. }\end{array}$ & $4,09 \%$ & 7 \\
\hline $\begin{array}{l}\text { As pessoas com deficiência têm a mesma capacidade desde } \\
\text { que a deficiência não iniba seus conhecimentos e capacidade } \\
\text { de aprendizado. }\end{array}$ & $4,12 \%$ & 7 \\
\hline $\begin{array}{l}\text { A universidade deve incentivar a inserção de pessoas com } \\
\text { deficiência, pois estas são poucas no ensino superior. }\end{array}$ & $4,68 \%$ & 8 \\
\hline Todos têm o mesmo dir eito. & $5,85 \%$ & 10 \\
\hline $\begin{array}{l}\text { Pessoas com deficiência têm a mesma capacidade intelectual e } \\
\text { profissional. }\end{array}$ & $7,06 \%$ & 12 \\
\hline $\begin{array}{l}\text { As pessoas com deficiência têm direito à educação, ao ensino } \\
\text { superior. }\end{array}$ & $11,70 \%$ & 20 \\
\hline Outras respostas ${ }^{1}$ & $52,57 \%$ & 66 \\
\hline TOTAL & $100,00 \%$ & 147 \\
\hline
\end{tabular}
encontram-se respostas tais como "as oportunidades são para todos", "as pessoas com deficiência precisam se inserir na sociedade", de grande valia, já que falamos que vivemos num país democrático", "deveria haver mais oportunidades para pessoas com deficiência", "deve-se especializar os professores", "é promover a cidadania", "é válido, desde que haja condições estruturais e profissionais para tal", "excelente, todos têm o objetivo de aprender, independente das diferenças", "existem pessoas com deficiência talentosas, a espera de oportunidade", "forma de igualdade de todos", "importante para as pessoas com deficiência e para a sociedade", "importante para o crescimento das instituiçōes de ensino superior" "importante, pois pessoas com deficiência têm necessidade de se aperfeiçoar para o mercado de trabalho",

Tabela 3: Opinião dos estudantes universitários sobre a educação inclusiva no ensino superior. Fonte: Dados da pesquisa.

Houve também respostas que enfocaram a responsabilidade do governo e das instituições de ensino superior sobre o ingresso de pessoas com deficiência na universidade, visto que 4,68\% responderam que "[...] a universidade deve incentivar a inserção de pessoas com deficiência, pois estas são poucas no ensino superior", 4,09\% disseram que "as instituições de ensino superior não estão preparadas para a educação inclusiva, o que a torna precária ou inexistente" e 3,51\% afirmaram que "o governo precisa incentivar e aumentar a inclusão de pessoas com deficiência no ensino superior (criar uma política de inclusão)". (Tabela 3). 
Algumas respostas condicionaram o ingresso das pessoas com deficiência no ensino superior ao tipo de deficiência ou a capacidade da pessoa com deficiência: 4,12\% afirmaram que "as pessoas com deficiência têm a mesma capacidade desde que a deficiência não iniba seus conhecimentos e capacidade de aprendizado". Cerca de $1,75 \%$ dos pesquisados respondeu que as pessoas com deficiência devem ingressar no ensino superior "se estiverem aptos e capazes para isso, tiverem o conhecimento mínimo necessário" (Tabela 3).

É importante relatar também que, apesar de poucas, houve respostas negativas em relação à inserção de pessoas com deficiência no ensino superior: $0,58 \%$ disseram que "as pessoas com deficiência, às vezes, não são responsáveis" e 0,58\% afirmaram que "isso é uma coisa absurda". (Tabela 3)

Segundo Andrade, Pacheco e Farias (2006), as pessoas com deficiência começaram a ingressar no ensino superior na década de 1950, apesar disso ainda são poucas as ações no sentido de facilitar o acesso dessas pessoas ao ensino superior e de conscientizar a sociedade que as pessoas com deficiência, apesar de terem algumas limitações, também têm habilidades e capacidade intelectual, independente do tipo de deficiência. Deve-se ressaltar também que as pessoas sem deficiência também têm dificuldades e limitações e que, muitas vezes, estas pessoas também não conseguem se adequar aos moldes tradicionais de ensino, muitas vezes fundados na educação bancária discutida por Freire (1987).

Andrade, Pacheco e Farias (2006) lembram também que, apesar das várias dificuldades existentes para a consolidação da educação inclusiva no ensino superior, nas últimas décadas do século $\mathrm{XX}$ aconteceram alguns progressos nas discussões sobre a inclusão de pessoas com deficiência, notadamente no campo jurídico, o que corrobora a posição de alguns estudantes que mencionaram a necessidade de incentivo do governo à educação inclusiva no ensino superior através de políticas públicas de inclusão dessas pessoas na sociedade.

Deve-se ressaltar também a necessidade de incentivo das instituições de ensino superior públicas e privadas em relação ao ingresso e permanência de pessoas com deficiência neste nível de ensino, conforme afirma Sassaki (2000, p. 1):

[...] para garantir que as medidas de acesso e permanência na universidade sejam implementadas de acordo com a nova visão potencial”, "importante/ necessário/ relevante / favorável / excelente iniciativa", "ninguém tem o direito de excluir o outro por ser diferente". 
de sociedade, de educação e de cidadania em relação à diversidade humana e as diferenças individuais - todas as pessoas devem ser aceitas e valorizadas pelo que cada uma possui para construir o bem comum, aprender e ensinar, estudar e trabalhar, cumprir deveres e usufruir direitos e ser feliz.

Algumas instituições de ensino superior de maior porte já dispõem de políticas de inclusão da pessoa com deficiência como o Projeto USP Legal, da Universidade de São Paulo (USP) (PIRES; LOPES; OLIVA FILHO, 2003) e o Programa de Apoio aos Portadores de Necessidades Especiais (PPNE) da Universidade de Brasília - UnB. (BASSETTE, 2007)

Apesar disso, as políticas de inclusão de pessoas com deficiência no ensino superior ainda são poucas. Uma das instituições que participaram dessa pesquisa aprovou, em 2008, o sistema de cotas para afrodescendentes, indígenas, quilombolas e pessoas com deficiência no Processo Seletivo Vestibular. Contudo, no que concerne a esta instituição, são necessárias outras políticas que visem dar suporte a este sistema de cotas recém-estabelecido para garantir que a inclusão torne-se uma realidade na referida instituição. Este fato justifica a preocupação de $4,12 \%$ dos pesquisados em relação ao estabelecimento de incentivos ao ingresso dessas pessoas e de 4,09\%, que afirmam que as universidades não estão preparadas e que educação inclusiva no ensino superior ainda é precária ou inexistente.

Cerca de 40,40\% das respostas analisadas mostraram-se incondicionalmente favoráveis à inclusão de pessoas com deficiência no ensino superior. (Tabela 3) Contudo, 5,87\% condicionaram o ingresso dessas pessoas ao tipo e nível de deficiência e 1,16\% manifestou-se contra. Assim, deve-se ressaltar que as pessoas com deficiência (independente do tipo de deficiência) têm os mesmos direitos à educação superior que uma pessoa sem deficiência como afirma o I Plano de Acção... (2006):

[...] a incapacidade não é inerente à pessoa, considerando-a como um conjunto complexo de condições, muitas das quais criadas pelo ambiente social, mudando o enfoque da anomalia ou deficiência para a diferença. Nesta perspectiva, está bem patente a valorização da responsabilidade colectiva no respeito pelos direitos humanos, na construção de uma sociedade para todos e 
no questionamento de modelos estigmatizantes ou pouco promotores da inclusão social.

\section{Presença de pessoas com deficiência no ensino superior: percepção dos estudantes pesquisados}

Quando foram perguntados se conheciam pessoas com deficiência que cursam ou cursaram o ensino superior (Gráfico 2), 63,94\% dos estudantes pesquisados responderam que sim, 34,69\% que não e 1,37\% não respondeu a questão.

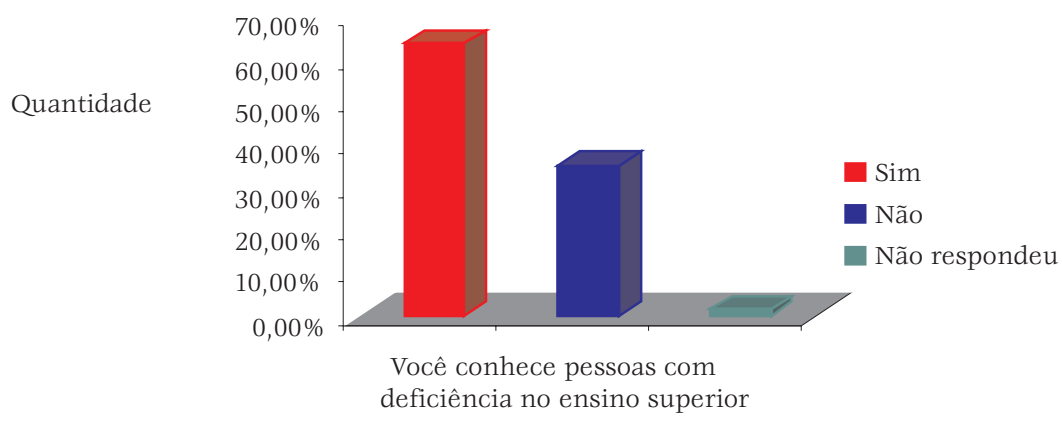

Gráfico 2: Você conhece pessoas com deficiência que no ensino superior? Fonte: Dados da pesquisa.

Perguntou-se também aos estudantes universitários pesquisados se eles tinham conhecimento do tipo de deficiência e do curso frequentado pelas pessoas com deficiência, que eles conheciam, que ingressaram no ensino superior. A maioria deles (cerca de 47,37\%) não soube especificar com exatidão o tipo de deficiência e 5,32\% não especificaram. Em relação ao curso frequentado pela pessoa com deficiência, 36,54\% relataram que era Ciências Contábeis e 11,54\% que era Letras, enquanto 7,69\% não souberam especificar.

Estes dados também demonstram que, embora ainda seja pouco expressivo o número de pessoas com deficiência na universidade, alguns deles, apesar dos obstáculos que enfrentam (não apenas no ensino superior; mas, antes dele, também no ensino fundamental e médio), conseguem ingressar no ensino superior graças ao esforço próprio e ao esforço de suas famílias, conforme lembra IumaTti (2006): "[...] aqueles que chegam à faculdade não 
foi porque encontraram uma estrutura educacional adequada (infelizmente, ainda há muito a melhorar), mas provavelmente decorre de outros fatores, como condições familiares mais favoráveis."

Deve-se considerar ainda que, para facilitar a conscientização, o convívio, o acesso e a permanência da pessoa com deficiência em todos os níveis de ensino, é importante diagnosticar o tipo e nível de deficiência. Tal diagnóstico deve ser feito, não com o intuito de discriminar ou estigmatizar a pessoa, mas sim para possibilitar-lhe um melhor tratamento e auxílio pedagógico por parte do docente e também melhorar sua qualidade de vida. O docente, ao saber do diagnóstico de seu aluno com deficiência (independente do tipo de deficiência), pode procurar informações, estudar sobre a deficiência com o intuito de conhecer as capacidades, habilidades e as dificuldades de seu aluno e, assim, desenvolver junto com ele, formas de minimizar as dificuldades e potencializar as habilidades.

O conhecimento do diagnóstico, além de auxiliar a família a incentivar e propiciar o desenvolvimento da pessoa com deficiência, contribui para a eliminação de termos pejorativos para se referir à deficiência, o que acontece, muitas vezes, não apenas devido ao preconceito, mas também pelo desconhecimento das pessoas em relação à deficiência. Esse desconhecimento contribui também para que muitas pessoas considerem as pessoas com deficiência como incapazes.

\section{Discriminação de pessoas com deficiência no ensino superior}

Ao serem perguntados se já haviam presenciado a discriminação de pessoas com deficiência no ensino superior (Gráfico 3), 85,71\% dos estudantes universitários afirmaram que não, enquanto $14,29 \%$ que sim, como uma das pessoas com deficiência, participante da pesquisa, que relatou a "falta de solidariedade com uma colega que precisou de apoio e não foi correspondida". 


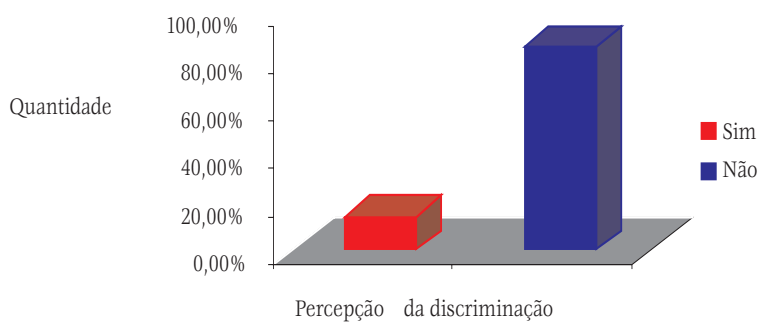

Gráfico 3: Percepção dos estudantes universitários sobre a discriminação de pessoas com deficiência no ensino superior. Fonte: Dados da pesquisa.

Ao serem convidados a justificar suas respostas em relação à discriminação de pessoas com deficiência no ensino superior, $73,43 \%$ dos estudantes universitários pesquisados preferiram não se manifestar, 3,49\% afirmaram não ter presenciado, enquanto 2,79\% afirmaram não conhecer pessoas com deficiência na instituição em que estudam.

Dentre os pesquisados, que mencionaram ter percebido o preconceito contra pessoas com deficiência no ensino superior, $2,79 \%$ afirmaram ter notado o descaso das pessoas em ajudar pessoas com deficiência que precisavam de ajuda, 4,90\% consideraram a falta de infraestrutura da instituição como uma forma de preconceito e 2,10\% relataram que "a direção da instituição não considerou a deficiência de uma aluna, que teve que subir as escadas nos dois primeiros anos de curso". Também foi citado o autopreconceito (preconceito contra si próprio) de pessoas com deficiência $(0,70 \%)$.

Segundo Garcia (1998), a educação não se restringe apenas à escola, mas também às relações sociais que os indivíduos travam entre si. Assim, a deficiência estigmatizada como "falha" ou "defeito" pode influenciar negativamente no desenvolvimento individual, visto que a forma como ela é tratada pode prover a autonomia ou a dependência da pessoa com deficiência. A discriminação da pessoa com deficiência pode fazer com que ela tenha uma baixa estima e não se considere capaz de fazer parte da sociedade, em detrimento de seus direitos e função social, resignando-se à exclusão. Para que isso não aconteça, é imprescindível a conscientização das pessoas e o combate a todas as formas de preconceito, uma vez que, conforme afirma a Convenção da Guatemala, as pessoas com deficiência tem o direito a não discriminação: 
[...] as pessoas portadoras de deficiência têm os mesmos direitos humanos e liberdades fundamentais que outras pessoas e que estes direitos, inclusive o direito de não ser submetidas a discriminação com base na deficiência, emanam da dignidade e da igualdade que são inerentes a todo ser humano. (GUATEMALA, 1999, p. 1)

Apesar disso, muitas pessoas com deficiência possuem dificuldade de adaptação social, conforme relatam Masini e Bazon (2005) em seu trabalho sobre a inclusão de pessoas com deficiência no ensino superior:

Em relação às próprias condições, os dados são mais convergentes no que dizem respeito à insegurança, à dificuldade em aceitar a deficiência, às dificuldades na escola, à falta de autonomia, à dificuldade na comunicação social e ao fato de segregarem-se convivendo apenas com pessoas portadoras de deficiência. (MASINI; BAZON, 2005, p.19)

Dessa forma, acredita-se que é muito importante a conscientização das pessoas em relação aos direitos e participação da pessoa com deficiência na sociedade, visando à extinção do preconceito. Contudo, é imprescindível que a pessoa com deficiência aceite a si próprio e as suas limitações; pois, assim, poderá aprender a contorná-las e a enfrentar o preconceito, seja ele qual for, pois será capaz de demonstrar que tem aptidões, independente da deficiência e que é capaz de realizar-se pessoal e profissionalmente.

\section{Considerações finais}

A Educação Inclusiva no ensino superior vem crescendo gradativamente no Brasil; contudo, ainda são poucas as pessoas com deficiência que conseguem ingressar e permanecer no ensino superior. Este aspecto demonstra a importância de se estudar a Educação Inclusiva no ensino superior e também como ela vem ocorrendo neste nível de ensino. Através dos dados obtidos neste estudo, verificou-se que a inclusão de pessoas com deficiência no ensino superior na cidade de Jequié ainda é tímida, assim como no restante do Brasil. Os dados permitiram notar também que a maioria dos estudantes universitários pesquisados já ouviu falar em inclusão $(91,16 \%)$ e a conceituaram como "inserção de pessoas 
com deficiência na sociedade" (17,65\%) e como "inserção de pessoas na educação / ensino superior" (14,38\%). Apesar da maioria dos participantes não definir, satisfatoriamente, o que vem a ser inclusão, os dados permitem notar também que os estudantes universitários pesquisados acham que a Educação Inclusiva no ensino superior é algo necessário e importante, uma vez que foram poucas as respostas negativas em relação ao ingresso de pessoas com deficiência neste nível de ensino. Percebeu-se também que a Educação Inclusiva ainda não é uma realidade constante nas instituições de ensino superior pesquisadas; visto que ainda é inexpressivo o número de pessoas com deficiência que chegam ao ensino superior na cidade de Jequié-BA e, de acordo com literatura, também em outras instituições de ensino superior no Brasil. Apesar disso, 63,94\% dos estudantes pesquisados afirmaram conhecer pessoas com deficiência no ensino superior e 14,29\% relataram já ter presenciado a discriminação à pessoa com deficiência no ensino superior. É importante ressaltar também que participaram deste estudo pessoas com deficiência que possuíam algum tipo de comprometimento físico. Este aspecto significa que as pessoas com deficiência auditiva, visual, mental e múltipla encontram obstáculos mais significativos para o ingresso e a permanência no ensino superior; uma vez que o docente precisa de recursos específicos para atender a estas pessoas (como Libras, Braille e métodos alternativos de ensino/aprendizagem), enquanto o maior obstáculo enfrentado pelas pessoas com deficiência física é a não adaptação da infraestrutura das instituições de ensino superior. Nas instituições de ensino superior pesquisadas, a Educação Inclusiva constitui-se em um desafio a ser concretizado através da elaboração de políticas de inclusão, que garantam o ingresso e a permanência das pessoas com deficiência no ensino superior para que elas possam exercer seu direito de participar da geração de conhecimento do país e se tornem mais qualificadas para o mercado de trabalho.

Hight education for handicapped people: with the word of university students of the city of Jequié - BA

Abstract: In order to know the opinion of university students about Higher Education for handicapped people, a questionnaire had been applied to 147 university students from the city of Jequié-BA. The analysis of the data revealed that there are still few handicapped people at higher education in this city and $91,16 \%$ of the searcheds have heard of inclusion. Approximately 
$14.29 \%$ of the searcheds said to have been witness of discrimination of handicapped people in institutions of higher education. These data have noted that handicapped people still have significant barriers to their entry and stay in higher education.

Keywords: Inclusive education. Handicapped person. Higher education.

\section{Referências}

ALUNOS com necessidades especiais ainda sofrem restrições nas universidades. Disponível em: < http://www.universia.com.br/ html/noticia/noticia_clipping_ddgdg.html >. Acesso em: 21 jun. 2007.

ANDRADE, M. S. A. de; PACHECO, M. L.; FARIAS, S. S. P. Pessoas com deficiência rumo ao processo de inclusão na educação superior. Conquer, Barreira, BA: Faculdade São Francisco de Barreiras, v. 26, 2006. Disponível em:< http://www.fasb.edu.br/revista/index.php/ conquer/article/view/27/9 > . Acesso em: 21 jun. 2007.

BASSETE, F. Número de portadores de deficiência nas universidades cresceu 179\% em 5 anos. 2007. Disponível em: < http:// g1.globo.com/Noticias/0,,MUI31348-5604,00.html >. Acesso em: 20 jun. 2007.

BENEVIDES, C. Brasil tem a melhor legislação para deficientes das Américas. 2004. Disponível em: < http://www.acesso.umic.pcm. gov.pt/news/270804e.htm >. Acesso em 26 mar. 2006.

BENZE, B.G. Metodologia científica e estatística. In: NUNES SOBRINHO, F. P.; NAUJORKS, M. I. (Org.). Pesquisa em educação:o desafio da qualificação. Bauru: EDUSC, 2001.

BRASIL. Decreto $n^{0}$ 3.298, de 20 de dezembro de 1999. Regulamenta a Lei $n^{\circ} 7.853$, de 24 de outubro de 1989, dispõe sobre a Política Nacional para a Integração da Pessoa Portadora de Deficiência, consolida as normas de proteção, e dá outras providências. Diário Oficial da União, Brasília, DF, 21dez 1999. Disponível em: < http:// www010.dataprev.gov.br/sislex/paginas/23/1999/3298.htm > . Acesso em: 25 jun. 2007.

CONSELHO NACIONAL DE SAÚDE. Resolução $n^{\circ}$ 196, de 10 de outubro de 1996. Disponível em: < conselho.saude.gov.br/docs/

Reso196.doc >. Acesso em: 20 set 2008.

COstA NETO, P. L. C. Estatística. São Paulo: Edgard Blucher, 1977.

FERREIRA, W. B. Educação inclusiva: será que sou a favor ou contra uma escola de qualidade para todos??? Inclusão: Revista da Educação Especial, Brasília. Secretaria de Educação Especial, v. 1, n.1, p. 40-46, out., 2005.

FREIRE, P. Pedagogia do oprimido. 17. ed. Rio de Janeiro: Paz e Terra, 1987. 
GARCEZ, L.; SACALOSKI, M. A psicologia e a fonoaudiologia na educação inclusiva: algumas considerações sobre as interfaces no processo educacional. Educação on-line, 2002. Disponível em:

< http://www.educacaoonline.pro.br/

Ba_psicologia_efonoaudiologia. asp?f_id_artigo $=392>$. Acesso em: 21 jun. 2007.

GARCIA, R. C. M. A educação dos indivíduos que apresentam seqüelas motoras: uma questão histórica. Cadernos CEDES, v. 19, n. 46, 1998. Disponível em: <http://www.scielo.br/scielo.php?script = sci_arttextEpid $=$ S010132621998000300008Elng $=$ enE $\mathrm{nrm}=$ iso $>$. Acesso em: 26 mar. 2006.

GIL, A. C. Métodos e técnicas de pesquisa social. 6. ed. São Paulo: Atlas, 2008.

GUATEMALA. Convenção interamericana para a eliminação de todas as formas de discriminação contra as pessoas portadoras de deficiência (Convenção da Guatemala). Guatemala, 28 maio 1999. Disponível em: < http://www.prefeitura.sp.gov.br/arquivos/secretarias/ saude/deficiencia/0008/Convencao_da_Guatemala.pdf. >. Acesso em: 22 jun. 2007.

IBGE. Contagem da população 2007. Disponível em:<www.ibge.gov.br/ home/estatistica/populacao/contagem2007/contagem_final/tabela1_1_16.pdf - 2007-12-21 >. Acesso em: 21 jun. 2007.

IUMATTI, A. B. Jovens com deficiência nas universidades. 2006. Disponível em: < http://www.portaldaretina.com.br/home/artigos. asp?cod=103 >. Acesso em: 21 jun. 2007.

MANTOAN, M.T.E. Educação escolar de deficientes mentais: problemas para a pesquisa e o desenvolvimento. Cadernos CEDES, v. 19, n. 46, 1998.

MASINI, E. A. F. S.; BAZON, F. V. M. A inclusão de estudantes com deficiência, no ensino superior. Trabalho apresentado na $28^{\text {a }}$ Reunião Anual da Anped, 16 a 19 de outubro de 2005, Caxambu, MG. Disponível em: <http://www.anped.org.br/reunioes/28/textos/gt20/ gt201195int.rtf>. Acesso em: 22 jun. 2007.

MRECH, L.M. O que é educação inclusiva? Educação on-line, 2005. Disponível em:<http://www.educacaoonline.pro.br/art_o_que _educacao_inclusiva.asp?f_id_artigo $=60$ >. Acesso em: 02 out. 2005.

NERI, M. et al. Retratos da deficiência no Brasil (PPD). Rio de Janeiro: FGV, IBRE, CPS, 2003. Disponível em: < http://www.fgv.br/ibre/ cps/deficiencia_br/index2.htm >. Acesso em: 25 jun. 2007.

PIRES, C. R.; LOPES, M. E.; OLIVA FILHO, S. M. Projeto USP Legal. Propondo uma política da USP referida à deficiência. Disponível em: < http://hygeia.fsp.usp.br/acessibilidade/cd/atiid2003/artigos/ ProjetoUSPLegal.doc. > . Acesso em: 22 jun. 2007. 
PRIETO, R.G. Políticas públicas de inclusão: compromissos do poder público, da escola e dos professores. Apeoesp, n. 16, 2003. Disponível em: < http://www.educacaoonline.pro.br/art_politicas_publicas_ de_inclusao.asp?f_id_artigo $=547>$. Acesso em: 16 out. 2005.

I PLANO de acção para a integração das pessoas com deficiências ou incapacidade: Resolução do Conselho de Ministros no 120/2006. Disponível em: <http://www.lerparaver.com/node/536>. Acesso em: 22 jun. 2007.

SALAMANCA. Declaração de Salamanca sobre princípios, políticas e práticas na área das necessidades educativas especiais. Salamanca, 10 de junho de 1994. Disponível em: < http://portal.mec.gov.br/ seesp/arquivos/pdf/salamanca.pdf. >. Acesso em: 22 jun. 2007.

SASSAKI, R. K. Inclusão: construindo uma sociedade para todos. 5. ed. Rio de Janeiro: WVA, 2000. In: ANDRADE, M. S. A.; PACHECO, M. L.; FARIAS, S. S. P. Pessoas com deficiência rumo ao processo de inclusão na educação superior. Disponível em: < http://www.fasb.edu. $\mathrm{br} / \mathrm{revista} /$ index.php/conquer/article/view/27/9 > . Acesso em: 21 jun. 2007.

SILVA, E. L.; MENEZES, E. M. Metodologia da pesquisa e elaboração de dissertação. 4. ed. Florianópolis: UFSC, 2005. 